\title{
Intestinal Manifestations of Generalized Lymphatic Anomaly
}

Takeshi Okamoto and Katsuyuki Fukuda

Key words: mesenteric cyst, congenital cyst, malformation, chyle

(Intern Med 59: 3241-3242, 2020)

(DOI: 10.2169/internalmedicine.5345-20)

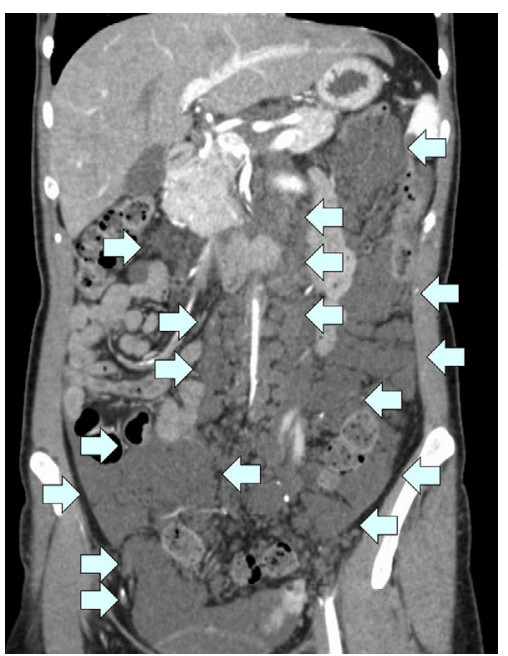

Picture 1.

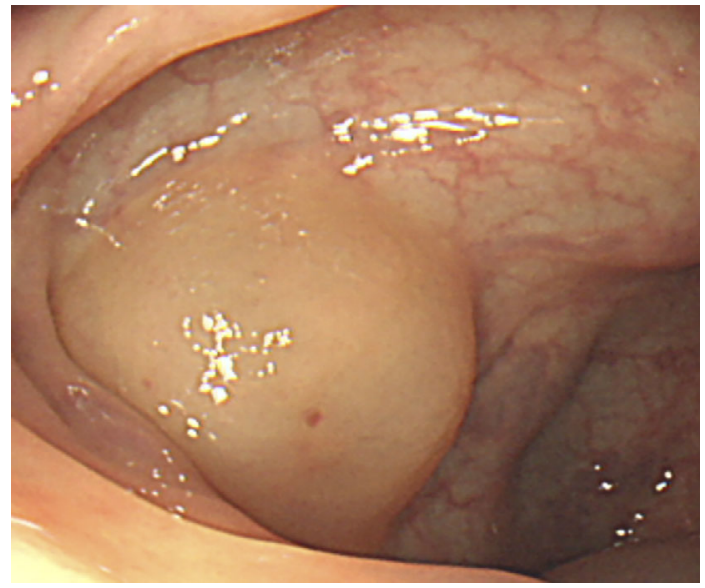

Picture 3.

A 27-year-old woman presented with abdominal pain. She had a history of multiple aneurysms and arteriovenous fistu-

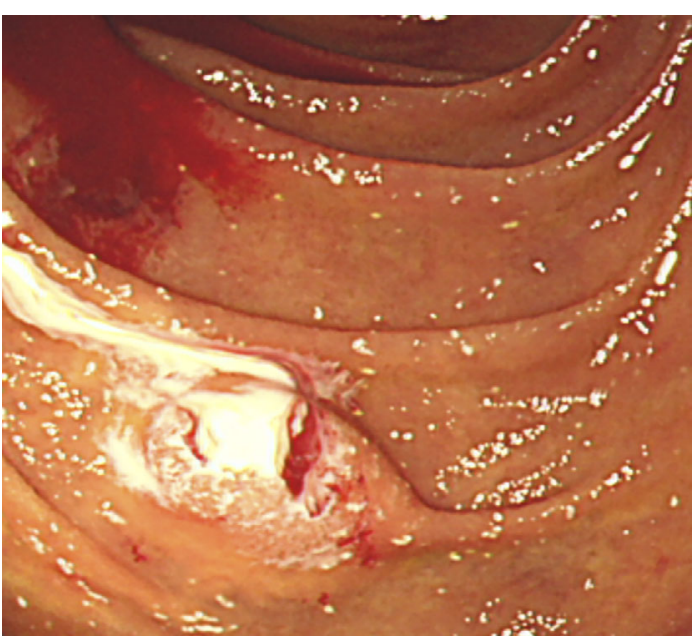

Picture 2.

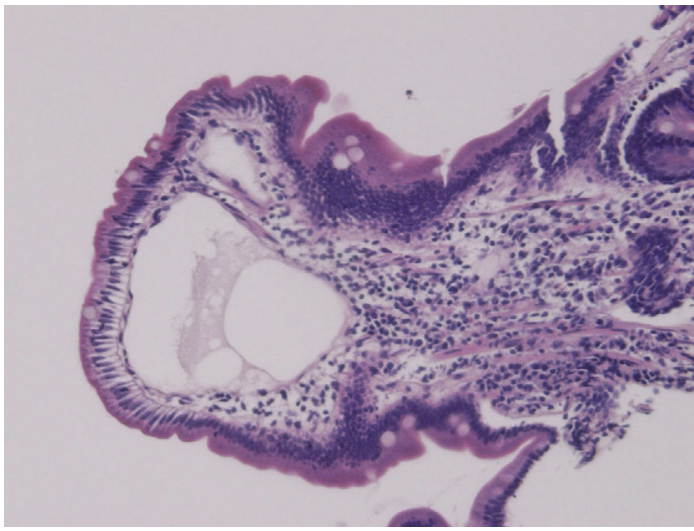

Picture 4.

las due to congenital vascular malformations. The findings of a physical examination and laboratory values were unremarkable. Contrast computed tomography revealed numerous cysts throughout the abdominal cavity (Picture 1). The 
patient was suspected of having mesenteric cysts secondary to generalized lymphatic anomaly. Esophagogastroduodenoscopy revealed multiple small cysts in the duodenum containing chyle (Picture 2). Multiple cysts were similarly observed in the colon (Picture 3). Pathology of the cysts revealed dilated ducts consistent with lymphangiectasia (Picture 4). The endoscopic findings were therefore believed to be intestinal manifestations of generalized lymphatic anomaly. Lymphatic malformations are a subset of vascular malformations that can give rise to multifocal cystic lesions that grow as children age (1). Intestinal manifestations of generalized lymphatic anomaly include mesenteric cysts, lymphangioma, and lymphangiectasia. Mesenteric cysts occur in approximately 1 out of every 100,000 adult hospital admissions (2).
The authors state that they have no Conflict of Interest (COI).

\section{References}

1. Wohlgemuth WA, Brill R, Dendl LM, Stangl F, Stoevesandt D, Schreyer AG. Abdominal lymphatic malformations. Radiologe $\mathbf{5 8}$ (Suppl): S29-S33, 2018.

2. Kurtz RJ, Heimann TM, Holt J, Beck AR. Mesenteric and retroperitoneal cysts. Ann Surg 203: 109-112, 1986.

The Internal Medicine is an Open Access journal distributed under the Creative Commons Attribution-NonCommercial-NoDerivatives 4.0 International License. To view the details of this license, please visit (https://creativecommons.org/licenses/ by-nc-nd/4.0/).

(C) 2020 The Japanese Society of Internal Medicine

Intern Med 59: 3241-3242, 2020 